\title{
Sintering of Ice Spheres under Different Thermal Conditions
}

\author{
Xuan Wang and Ian Baker
}

Thayer School of Engineering, Dartmouth College, Hanover, New Hampshire USA

Arrays of ice spheres, as geometrically-simplified specimens for complex snow structures, can be used to observe the microstructural evolution and investigate the mass transfer process during snow metamorphism. In this paper, 1-D arrays of polycrystalline ice spheres were produced using the method of Chen et al. [1] and placed in a precisely-controlled temperature gradient set-up. Different vapor transfer directions were applied to investigate the formation of faceted crystals and depth hoar structures. We also examined the effects of an imposed alternating temperature gradient (TG) along the ice spheres, which simulated the sintering condition occurring in the daily cycles of radiative heating and cooling in the topmost $20 \mathrm{~cm}$ of the snow layer [2].

Spherical ice spheres were produced by freezing $0^{\circ} \mathrm{C}$ deionized, degassed water droplets in liquid nitrogen. An array of ice spheres of $\sim 3 \mathrm{~mm}$ diameter was arranged vertically inside an acrylic tube sealed with two copper caps. The acrylic tube was placed into a home-built temperature gradient setup. The evolutions of vertical arrays of ice spheres were investigated under four conditions for $48 \mathrm{~h}$, with two groups of alternating TG metamorphism (ATG-1, ATG-2) and two groups of unidirectional TG metamorphism (TG-1, TG-2), see Table 1. A Skyscan 1172 micro-CT was used to examine the ice sphere specimens periodically using pixel size of $7.8 \mu \mathrm{m}$. The specimens were scanned every $12 \mathrm{~h}$, and for the ATG conditions the TG direction was reversed every $12 \mathrm{~h}$.

The mass transfer mechanisms under the four thermal conditions can be quantified by the evolution of the neck area and the neck position (Figure 1). For ATG-1 and ATG-2, the neck area increased while the neck positions fluctuated as the TG direction was cycled and returned to the original position. The overall phenomenon is similar to that for isothermal sintering: the vapor diffuses from the spheres to the neck, but the neck position does not change. For TG-1 and TG-2, the neck area increased over time and the neck positions changed monotonously depending on the vapor transfer direction. Figure 2 shows the final neck morphologies for ATG-1, TG-1, and TG-2. Figure 2a shows a porous neck with rounded protrusions, while Figure 2(b, c) shows faceted and depth hoar structures around the neck. When the top was colder than the bottom, the cup-like depth hoar structures grew downwards, which means the inner surface faced downwards. For the opposite TG condition, the depth hoar structure grew upwards. In order to model the interaction between the depth hoar structure formation and temperature distribution, we increased our scan frequency under the TG-2 thermal condition and eight 2D vertical cross section images of ice spheres in different times were imported into $\mathrm{COMSOL}^{\mathrm{TM}}$ to model the temperature and vapor flux distribution. The problem was solved by considering only the thermal conduction in the ice and air domains. Figure 3 shows the modeled temperature and vapor flux distribution over time. The modeled vapor flux predicted the morphology in the next scan. The newly developed ice crystals around the neck evolved from the thin plates into faceted crystals and depth hoar structures, which directly simulated the formation of depth hoar structure under natural snow TG metamorphism.

References:

[1] Chen, S., I. Baker, and H.J. Frost, Surface instability and mass transfer during the bonding of ice spheres. Philosophical Magazine, 2013. 93(23): p. 3177-3193. 
[2] Pinzer, B. and M. Schneebeli, Snow metamorphism under alternating temperature gradients: Morphology and recrystallization in surface snow. Geophysical Research Letters, 2009. 36(23).

[3] The authors acknowledge funding from Army Research Office contract 51065-EV.

\begin{tabular}{|c|c|c|c|c|c|c|c|c|}
\hline & \multicolumn{2}{|c|}{ ATG-1 } & \multicolumn{2}{c|}{ ATG-2 } & \multicolumn{2}{c|}{ TG-1 } & \multicolumn{2}{c|}{ TG-2 } \\
\hline Time(h) & Top $\left({ }^{\circ} \mathrm{C}\right)$ & Bottom $\left({ }^{\circ} \mathrm{C}\right)$ & Top $\left({ }^{\circ} \mathrm{C}\right)$ & Bottom $\left({ }^{\circ} \mathrm{C}\right)$ & Top $\left({ }^{\circ} \mathrm{C}\right)$ & Bottom $\left({ }^{\circ} \mathrm{C}\right)$ & Top $\left({ }^{\circ} \mathrm{C}\right)$ & Bottom $\left({ }^{\circ} \mathrm{C}\right)$ \\
\hline 0 & -10 & -8 & -8 & -10 & -10 & -8 & -8 & -10 \\
\hline 12 & -8 & -10 & -10 & -8 & -10 & -8 & -8 & -10 \\
\hline 24 & -10 & -8 & -8 & -10 & -10 & -8 & -8 & -10 \\
\hline 36 & -8 & -10 & -10 & -8 & -10 & -8 & -8 & -10 \\
\hline 48 & & & & & Final Scan & & & \\
\hline
\end{tabular}

Table 1. Boundary conditions for ATG-1, ATG-2 and TG-1, and TG-1 conditions.
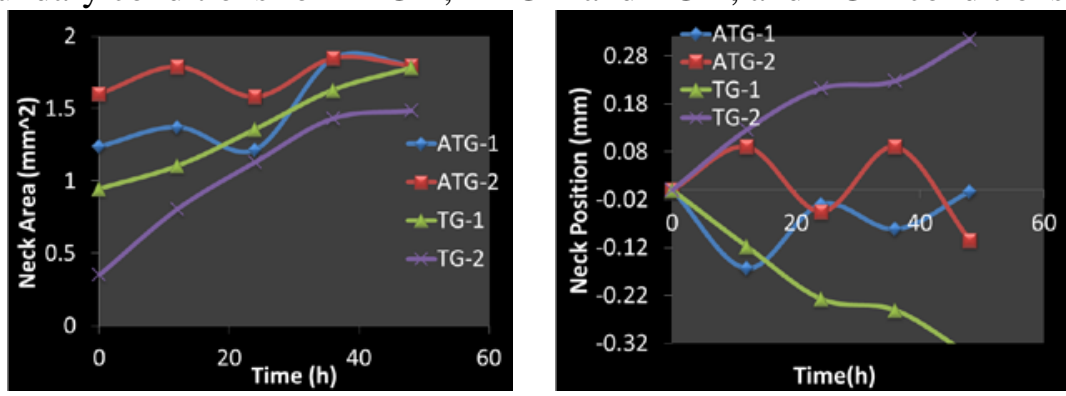

Figure 1. The neck area and neck position evolutions for ATG-1, ATG-2, TG-1, TG-2 conditions.

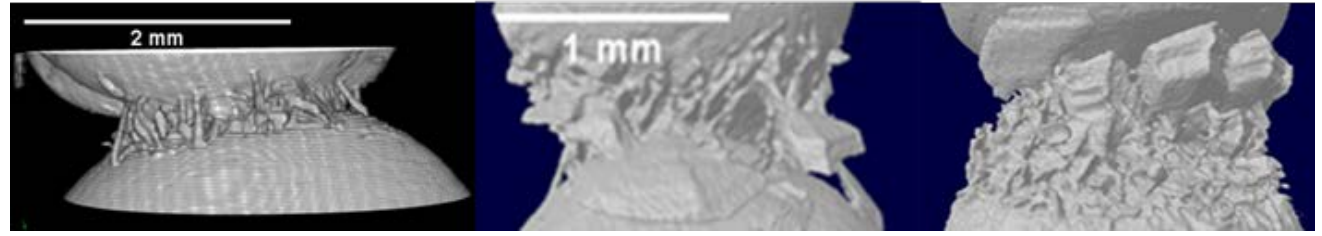

Figure 2. The final morphologies of the neck under (a) ATG-1, (b) TG-1, (c) TG-2 conditions.

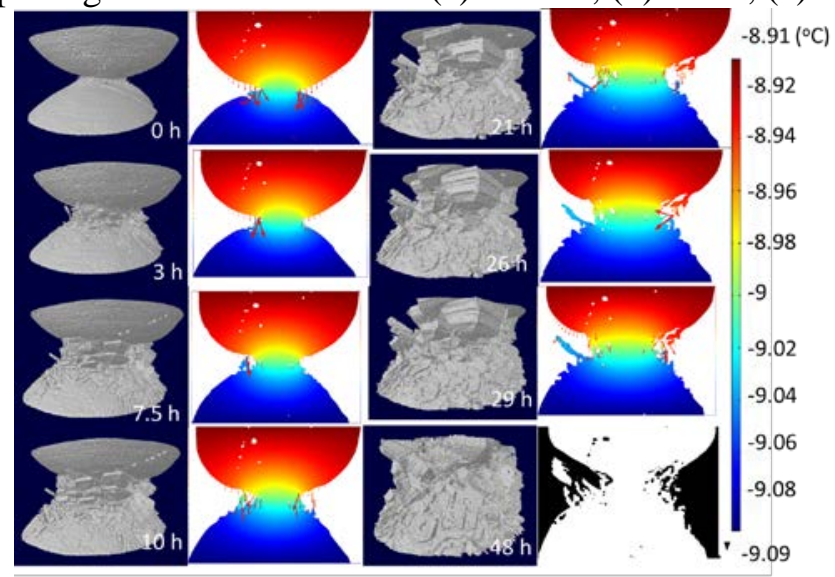

Figure 3. Interaction between depth hoar structure formation and the temperature distribution calculated using $\mathrm{COMSOL}^{\mathrm{TM}}$. 